\title{
ELECTRON PARAMAGNETIC RESONANCE AND SUPERPOSITION MODEL ANALYSIS OF ZERO FIELD SPLITTING FOR $\mathrm{Mn}^{2+}$ IN DOUBLE NITRATES
}

\author{
V.K. Jain and V. Prakash \\ Department of Physics, M.D. University, Rohtak-124 001, India
}

(Received July 12, 1993)

\begin{abstract}
Electron paramagnetic resonance of $\mathrm{Mn}^{2+}$ in $\mathrm{La}_{2} \mathrm{Zn}_{3}\left(\mathrm{NO}_{3}\right)_{12} \cdot 24 \mathrm{H}_{2} \mathrm{O}$ single crystals is studied at $\approx 9.45 \mathrm{GHz}$. $\mathrm{Mn}^{-2+}$ substitutes for $\mathrm{Zn}^{2+}$ sites. The spin-Hamiltonian parameters are evaluated at $\approx 290 \mathrm{~K}$. The superposition model has been applied to the zero-field splitting parameter $D$ for $\mathrm{Mn}^{2+}$ in $\mathrm{Ce}_{2} \mathrm{Mg}_{3}\left(\mathrm{NO}_{3}\right)_{12} \cdot 24 \mathrm{H}_{2} \mathrm{O}$ and $\mathrm{La}_{2} \mathrm{Mg}_{3}\left(\mathrm{NO}_{3}\right)_{12} \cdot 24 \mathrm{D}_{2} \mathrm{O}$ at both sites. It is shown that the calculated values of $D$ are in agreement with the experimental values if local relaxation effects are taken into account.
\end{abstract}

PACS numbers: $76.30 . \mathrm{Fc}$

\section{Introduction}

Since the electron paramagnetic resonance (EPR) of $\mathrm{Mn}^{2+}$ is easily detectable even at room temperature, many EPR investigations result in the determination of zero-field splitting (ZFS) parameters. In most of these systems $\mathrm{Mn}^{2+}$ ions were coordinated by oxygens and the ZFS parameter $D$ is quite sensitive with respect to small structure changes. The calculations of ZFS follow two lines [1]. In the first which is referred to as ab initio calculations, ZFS is generally reckoned using an electrostatic model of the crystal field, together with one or more of the splitting mechanisms. The second method of estimating ZFS is by the empirical superposition model (SPM) [2]. SPM has been applied to understand the ZFS of $\mathrm{Mn}^{2+}$ and to gain some useful information on the crystalline environment of these ions in a number of crystals [1]. This paper describes the EPR studies of $\mathrm{Mn}^{2+}$ in $\mathrm{La}_{2} \mathrm{Zn}_{3}\left(\mathrm{NO}_{3}\right)_{12} \cdot 24 \mathrm{H}_{2} \mathrm{O}$ (LZN) single crystals at $290 \mathrm{~K}$ and SPM analysis of the ZFS parameter $D$ of $\mathrm{Mn}^{2+}$ has been described in isomorphous $\mathrm{Ce}_{2} \mathrm{Mg}_{3}\left(\mathrm{NO}_{3}\right)_{12} \cdot 24 \mathrm{H}_{2} \mathrm{O}(\mathrm{CMN})$ and $\mathrm{La}_{2} \mathrm{Mg}_{3}\left(\mathrm{NO}_{3}\right)_{12} \cdot 24 \mathrm{D}_{2} \mathrm{O}$ (DLMN). 


\section{Crystal structure}

The crystal structure of CMN [3], $\mathrm{La}_{2} \mathrm{Mg}_{3}\left(\mathrm{NO}_{3}\right)_{12} \cdot 24 \mathrm{H}_{2} \mathrm{O}$ (LMN) [4] and DLMN [5] isomorphous with LZN has been studied. The primitive cell containing one formula unit is rhombohedral. For CMN, lattice constant $a=1.3165 \mathrm{~nm}$ and $\alpha=49.37^{\circ}$ [3]. The space group is $R \overline{3}$. The unit cell contains three divalent ions situated at two different lattice sites with the point symmetery $C_{3 i}$ (site I) and the other two divalent ions occupy lattice sites with the point symmetry $C_{3}$ (site II). The divalent ions are surrounded by six water molecules forming with the central ion a nearly octahedral complex. Each trivalent ion is coordinated with 12 oxygens belonging to six nitrate ions, located at the corners of a somewhat irregular icosahedron.

\section{Experimental}

Single crystals of LZN were grown at room temperature $(\approx 290 \mathrm{~K})$ by slow evaporation of an aqueous solution. $\mathrm{Mn}^{2+}$ was introduced into the host lattice by adding $(0.2 \mathrm{wt} \%)$ manganese nitrate. The crystal grows in flat hexagonal plates, the plane of which is perpendicular to the trigonal axis. The EPR experiments were performed on a JEOL FE-3X homodyne spectrometer operating at $\approx 9.45 \mathrm{GHz}$ equipped with a $\mathrm{TE}_{011}$ cylindrical cavity and $100 \mathrm{kHz}$ field modulation. A speck of powdered DPPH used as a field marker (taking $g_{\mathrm{DPPH}}=2.0036$ ) was inserted simultaneously into the sample cavity. The crystals were mounted on quartz rods. The angular variation studies were done using a JES-UCR-2X sample angular rotating device.

\section{Results and discussion}

For an arbitrary orientation of the crystal the EPR spectrum consists of a number of lines corresponding to allowed and forbidden transitions. Angular variation studies of $\mathrm{Mn}^{2+}$ spectra reveal the presence of two inequivalent $\mathrm{Mn}^{2+}$ centres of unequal intensity. $\mathrm{Mn}^{2+}$ substitutes for $\mathrm{Zn}^{2+}$ and shows the spectrum of two $\mathrm{Mn}^{2+}$ complexes. The spectrum having greater intensity is due to $\mathrm{Mn}^{2+}$ substituting for $\mathrm{Zn}^{2+}$ at site II while the spectrum having lower intensity is due to $\mathrm{Mn}^{2+}$ at site I. The $\mathrm{Mn}^{2+}$ centre occuping the site II is more intense because there are twice as many II sites as I sites. It was found that the principal $z$ axes of two $\mathrm{Mn}^{2+}$ complexes are along the trigonal axis ( $c$ axis) and $x$ axes perpendicular to the $c$ axis. The spectra of $\mathrm{Mn}^{2+}$ showing large ZFS (site I) were measured for various angles of the magnetic field relative to $c$ axis. A $\pi / 3$ rotational symmetry of the spectrum was observed when the crystal was rotated about the $c$ axis.

The EPR spectrum of $\mathrm{Mn}^{2+}$ for both sites can be described by a spin Hamiltonian of the form [6]

$$
\begin{aligned}
\mathcal{H}= & \beta_{\mathrm{e}} g_{\|} S_{z} B_{z}+\beta_{\mathrm{e}} g_{\perp}\left(S_{x} B_{x}+S_{y} B_{y}\right)+D\left(S_{z}^{2}-35 / 12\right) \\
& -(7 / 36)(a-F)\left[S_{z}^{4}-(95 / 14) S_{z}^{2}+81 / 16\right]
\end{aligned}
$$




$$
\begin{aligned}
& +a(\sqrt{2} / 36)\left\{S_{z}\left[S_{+}^{3} \exp (-3 \mathrm{i} \phi)+S_{-}^{3} \exp (3 \mathrm{i} \phi)\right]+\left[S_{+}^{3} \exp (-3 \mathrm{i} \phi)\right.\right. \\
& \left.\left.+S_{-}^{3} \exp (3 \mathrm{i} \phi)\right] S_{z}\right\}+A_{\|} S_{z} I_{z}+A_{\perp}\left(S_{x} I_{x}+S_{y} I_{y}\right)
\end{aligned}
$$

where the $z$ axis is parallel to the $c$ axis of the crystal. The symbols have their usual meaning and $S=I=5 / 2$ for $\mathrm{Mn}^{2+}$. Using the above spin Hamiltonian, the $\mathrm{Mn}^{2+} \mathrm{EPR}$ spectra are analysed and the best fit parameters (all ZFS and hyperfine splitting parameters are in units of $10^{-4} \mathrm{~cm}^{-1}$ ) thus obtained at $290 \mathrm{~K}$, for site I, are: $D=-184(1), a-F=-6(1), A_{\|}=-89(1), A_{\perp}=-89(1), g_{\|}=2.003(1)$, $g_{\perp}=2.005(2)$ and for site II are: $D=13(2), a-F=7(1), A_{\|}=-89(2)$, $A_{\perp}=-90(2), g_{\|}=2.002(2), g_{\perp}=2.003(2)$. The signs of the parameters are relative assuming $A_{\|}$to be negative [1]. It is clear that the ZFS parameter $D$ is very different for the two sites indicating that the two sites differ greatly in the crystal field seen by the ions.

Assuming ZFS to be solely due to the distortion of the first coordinate sphere of oxygens of water molecules, the experimental ZFS can be compared with those calculated from the crystal structure data for the pure host compound. SPM allows one such a comparison [1,2]. SPM is based on two assumptions: (i) ZFS is due to the close neighbour ions and (ii) ZFS is given by a sum of axially symmetric contributions of the $i$ ligands of $\mathrm{MX}_{i}$ unit. The contribution of more distant neighbours as well as interaction between ligands, are ignored. The ZFS paramter $D$ is written as $[1,2]$ :

$$
D=\sum K_{2}^{0}\left(\theta_{i}, \phi_{i}\right) \bar{b}_{2}\left(R_{i}\right)
$$

where $K_{2}^{0}=\left(3 \cos ^{2} \theta_{i}-1\right) / 2$, the summation runs over all ligands; $R_{i}, \theta_{i}$ and $\phi_{i}$ are the spherical coordinates of the $i$-th ligand (the paramagnetic ion is placed at the origin). The dependence of $\bar{b}_{2}(R)$ on metal-ligand distance $R$ can be approximated by

$$
\bar{b}_{2}(R)=\bar{b}_{2}\left(R_{0}\right)\left(R_{0} / R_{i}\right)^{t_{2}}
$$

the exponent $t_{2}=7 \pm 1$ for $\mathrm{Mn}^{2+}$. $R_{0}=0.22 \mathrm{~nm}$ is the reference distance for $\mathrm{Mn}^{2+}$ surrounded by six oxygens and $\bar{b}_{2}=-0.05 \mathrm{~cm}^{-1}[1]$.

In CMN, $\mathrm{Mg}^{2+}$ at site $\mathrm{I}$ is surrounded by six water molecules at a distance $R=0.2058 \mathrm{~nm}$ and at site II is surrounded by two sets of three oxygens of water ligands at distance 0.2056 and $0.2058 \mathrm{~nm}$ [3]. The angle $\theta$ which $\mathrm{Mg}-\mathrm{O}$ makes with $c$ axis at site $\mathrm{I}$ is $54.10^{\circ}$ and for site II are $54.83^{\circ}$ and $123.69^{\circ}$. The ZFS parameter $D$ calculated by using (1) and (2) are $-76 \times 10^{-4} \mathrm{~cm}^{-1}$ and $104 \times 10^{-4} \mathrm{~cm}^{-1}$ for site I and II, respectively. The experimentally determined $D$ values for $\mathrm{Mn}^{2+}$ doped CMN at site I and II are -188.7 and $19.4 \times 10^{-4} \mathrm{~cm}^{-1}$, respectively [7]. SPM predicts the correct sign for both sites. The calculated value of $D$ for site I is smaller than the experimental value and larger for site II.

In these calculations, the assumption has been made that the crystalline structure in the vicinity of the magnetic ion is unchanged from those of the host lattice. The difference in calculated and experimental values of $D$ may be principal results from the local relaxation. It has been shown that if $R$ (metal-ligand bond distance) is larger than normal $\mathrm{Mn}$-ligand bond distance, the introduction of substitutional $\mathrm{Mn}^{2+}$ gives rise to an inward relaxation while the opposite occurs for $R$ smaller than $\mathrm{Mn}$-ligand bond distance [8]. The ionic radii of $\mathrm{Mn}^{2+}$ and 
$\mathrm{Mg}^{2+}$ are 0.080 and $0.066 \mathrm{~nm}$, respectively [9]. Therefore, $\mathrm{Mn}^{2+}$ substitution for $\mathrm{Mg}^{2+}$ would allow one some expansion of $\mathrm{O}^{2-}$ octahedron around $\mathrm{Mn}^{2+}$. A movement of oxygen along the $c$ axis is assumed such that Mn-oxygen bond length increases from that of the $\mathrm{Mg}$-oxygen. This causes a change in the value of $\theta$. It is found that an increase of about $1.45 \%$ in bond length (from 0.2058 to $0.2088 \mathrm{~nm}$ ) causes the angle $\theta$ to change to $53^{\circ}$ for site I. An increase of about $0.9 \%$ in bond length of $\mathrm{Mg}(2)-\mathrm{O}(2)$ (from 0.2055 to $0.2073 \mathrm{~nm}$ ) and $\mathrm{Mg}(2)-\mathrm{O}(3)$ (from 0.2058 to $0.2076 \mathrm{~nm}$ ) causes $\theta$ to change to $54.24^{\circ}$ and $124.39^{\circ}$, respectively. These values of $R$ and $\theta$ lead to $D$ values -187 and $20 \times 10^{-4} \mathrm{~cm}^{-1}$ for site I and II, respectively. Similar SPM analysis has been performed for $\mathrm{Mn}^{2+}$ in DLMN. It is shown that deuteration of LMN has no effect on $\mathrm{Mn}^{2+}$ parameters [10]. Therefore the $D$ values are taken from $\mathrm{Mn}^{2+}$ doped LMN [11]. The $D$ values of $\mathrm{Mn}^{2+}$ at sites I and II are -188.6 and $21 \times 10^{-4} \mathrm{~cm}^{-1}$, respectively. The values of $D$ obtained from SPM using structural data $[3,5]$ are -64 and $108 \times 10^{-4} \mathrm{~cm}^{-1}$ for site $I$ and II, respectively. An increase in bond length, of about $1.63 \%$ for $\mathrm{Mg}(1)-\mathrm{O}(1)$ and about $1.1 \%$ for $\mathrm{Mg}(2)-\mathrm{O}(2)$ and $\mathrm{Mg}(2)-\mathrm{O}(3)$ gives values of $D$ in agreement with the experimental values. Agreement between calculated and experimental values is also obtained for $\mathrm{LMN}: \mathrm{Mn}^{2+}$ if $\mathrm{Mg}(1)-\mathrm{O}(1)$ bond length is increased by $1.8 \%$ and that of $\mathrm{Mg}(2)-\mathrm{O}(2)$ and $\mathrm{Mg}(2)-\mathrm{O}(3)$ by $0.4 \%$. A change of bond lengths of about 3-4 \% is observed from EXAFS measurements in $\mathrm{KZnF}_{3}, \mathrm{KCdF}_{3}$ and $\mathrm{CaF}_{2}$ doped with $\mathrm{Mn}^{2+}[8,12]$. SPM analysis for the ZFS parameter $D$ of $\mathrm{Mn}^{2+}$ in LZN could not be performed because crystal structure has not been determined. However, it is expected that $\mathrm{Mn}-\mathrm{O}$ bond length in LZN would be larger than $\mathrm{Zn}-\mathrm{O}$ bond length as the ionic radii of $\mathrm{Mn}^{2+}$ is larger than of $\mathrm{Zn}^{2+}$ [9]. Therefore, an outward relaxation takes place when $\mathrm{Mn}^{2+}$ substitutes for $\mathrm{Zn}^{2+}$ in LZN. A comparison of the ZFS parameter $D$ in double nitrates indicates nearly the same value for site I [1]. The value of $D$ for site II is very different from that of site I but has nearly the same value in various double nitrates [1].

Therefore, it may be conluded that whatever the difference between the structure of double nitrates as regards to lattice parameters and coordinates of ions, the substitution of $\mathrm{Mn}^{2+}$ in place of divalent cation forms $\left[\mathrm{Mn}\left(\mathrm{H}_{2} \mathrm{O}\right)_{6}\right]^{2+}$ complexes which have nearly the same configuration irrespective of the double nitrate. This indicates that $\left(3 \cos ^{2} \theta_{i}-1\right) / R_{i}^{7}$ has nearly the same value for $\mathrm{Mn}$ complexes in various double nitrates.

\section{Acknowledgments}

This work is supported by the Council of Scientific and Industrial Research, New Delhi.

\section{References}

[1] V.K. Jain, G. Lehmann, Phys. Status Solidi B 159, 495 (1990); S.K. Misra, J.S. Sun, Magn. Reson. Rev. 16, 57 (1991).

[2] D.J. Newman, B. Ng, Rep. Prog. Phys. 52, 699 (1989); D.J. Newman, W. Urban, Adv. Phys. 24, 793 (1975). 
[3] A. Zalkin, J.D. Forrester, D.H. Templeton, J. Chem Phys. 39, 2881 (1963).

[4] M.R. Anderson, G.T. Jenkin, J.W. White, Acta. Crystallogr. B 33, 3933 (1977).

[5] A.M. Balagurov, E. Borca, M. Dlouha, Z. Gheorghiu, G.M. Mironova, V.B. Zlokazov, Acta Crystallogr. A 35, 131 (1979).

[6] S. Geschwind, Phys. Rev. 121, 363 (1961).

[7] V.P. Seth, V.K. Jain, R.S. Bansal. Phys. Status Solidi B 129, 375 (1985).

[8] M.T. Barriuso, M. Moreno, Phys. Rev. B 29, 3623 (1984).

[9] CRC Hanbook of Chemistry and Physics, Ed. D.R. Lide, CRC Press, Boca Raton 1990-91, p. 12-I.

[10] H.S. Maldonado, M.G. Gutierrez, C. Zarate, G.E. Barberis, Phys. Status. Solidi B 81, K27 (1977).

[11] B.M. Brandt, D. Van Ormond, T. Thalhammer, Phys. Lett. 19, 549 (1965); D. Van Ormond, T. Thalhammer, Phys. Lett. 14, 169 (1963).

[12] J.H. Barkyoumb, A.N. Mansour, Phys. Rev. B 46, 8768 (1992). 